\title{
Farmers Involved in the Production of Agricultural Standardization Factors Analysis
}

\author{
Qin Luo \\ Sichuan Agricultural University, Room 509, 6 Apartment, Wenjiang Chengdu Sichuan, China \\ E-mail: 452439224@qq.com \\ Xiumin $\mathrm{Wu}$ (Corresponding author) \\ Sichuan Agricultural University, Graduate Office, Room 209, Yaan Sichuan, China \\ E-mail: 452439224@qq.com \\ Hao Wang \\ Sichuan Agricultural University, Wenjiang Chengdu Sichuan, China \\ E-mail:452439224@qq.com
}

Based on the Data of Sichuan

Received: February 28, 2011 Accepted: March 15, 2011 doi:10.5539/jas.v3n3p251

This article is National Philosophy and Social Science Foundation project "Agricultural Product Quality Safety Security System" (item number: 09XJY024) part of the research results.

\begin{abstract}
This paper, uses the survey data of 104 households in the city of Sichuan by the method of Logistic regression analysis, has analysised factors of the farmers who involved in agricultural standardization of production or not. Research shows that the cognitive level of standardization, awareness of pesticides' hazards, their own age and family numbers have significantly influenced on the famers who involved in standardization of agricultural production. Then there are some recommends for solving.
\end{abstract}

Keywords: Farmers'active, Agricultural Standardization, Factors Affecting

\section{Introduction}

The "three rural issues" has always been the core issue in China. With the food safety issues at home and abroad happened frequently, such as avian influenza, Sudan 1, the melamine incident, etc., the safety of agricultural products challenge the "three rural" issues. In a long period of time, small-scale farmers are not only the basic unit of agricultural operations but also the main agricultural productors. How to make farmers protect the safety of agricultural products is one of the problems which the government faced to solve. According to the definition of National Standards Committee, agricultural standardization is a high quality, commercial, large-scale, intensive process of agricultural modernization through making scientific and technological achievements into the standards, making agricultural production and business activities high efficiency, low cost, increasing the number of agricultural products, improving the quality of agricultural products (Zhang Lingguang, 2004). As far as the above-mentioned, agricultural standardization can help improve the level of agricultural products'safety. Therefore, according to the actual situation in China, discussing standardization of agricultural production in the process of household behavior, analysising the impact factors of the farmer who involved in agricultural standardization, is benefit to guide farmers to actively participate in standardization of agricultural production and improve quality of agricultural products.

The academic research, about the behavior of farmers who involved in standardization of agricultural production, is most of judgement by experience and summary from work (Wang Fang, 2007). Farmers act on food safety mainly be affected by education level and income level (Qiao Juan, 2009; Feng Zhongze, 2007). In vegetable safety control, household behavior will be impacted by cognition of the pesticides and environment, vegetable growing area, the moral sense of responsibility, training and learning situation, joined the case of industrial organization, policies and regulations and so on.(Zhou Jiehong, 2009). In the use of pollution-free, organic agricultural products and the behavior of pesticide application, farmers are often affected by demographic and land characteristics of farmers, farmers ability characteristics and other factors (Zhang Ynhua et al, 2004; Hongmei Li et al, 2007; Liu Ruifeng et al, 2009). Xiong Minghua (2005), seting from the farmer who join into 
standard products organization, thinks that order agriculture, training, books and information as well as frequency of contacting with agricultural workers and other factors will be affected farmers activities. In addition, Louxu Hai etc.(2007) from the farmers involved in the standardization organization point of view, find that organization form, farm family characteristics, awareness and impact of the production characteristics are the impact factors.

Consedering above-mentioned, the literatures are mostly confronted by macro view. And by the regional differences, it is necessary to analysis the famers'influencing factors in the different demonstration zone, standing on the behavior of farmers who involved in standardization of agricultural production. Therefore, this paper attempts to use Logistic model, based the actual survey data in Sichuan, and draw some relevant conclusions and policy recommendations.

\section{Theoretical framework and research hypotheses}

Farmers'behavior is complex. Theory of Planned Behavior(TPB) is the wider use of the theory to analysis the individual behavior. It thinks that individual behavior is affected by attitude, subjective norm, perceived behavior. Combined with farmers' Independent decision-making, and the double objectives(Zhou Jiehong, 2006), according to the limited rationality of Western economics theory,farmers who are involved in agricultural standardization is based on limited subjective choices, made under particular act rationally, and then made its theoretical framework, shown in Figure 1.

Therefore, according to the influence of farmers who anicipate in agrucalture standardization, author can surpose that the following four hypotheses:

\subsection{Farmers personal characteristic variables affect farmer who participates in agricultural production}

Farmers personal characteristics include gender (X1), age of household head (X2), as well as educational level (X3). Among them, the older the more conservative; from a gender perspective, women in general more conservative than men; education can be expressed in terms of farmers' initiative to accept new things, the higher the educational level, initiative will be enhanced (Li Dongmei, etc., 2009 ). This paper assumes that the behavior of farmers involved in agricultural standardization would decrease with age's increasing, women will be less involved in the standardization; with the increased level of education, it will promote the farmers involved in agricultural standardization.

\subsection{Family characteristic variables affect farmers to involve in agricultural production}

Family characteristic variables include household size (X4), the main source of income (X5), the per capita net income (X6). Agricultural standardization which can increase in the quantity and quality of agricultural products, will give farmers a certain extent on the revenue growth. Considering the interests of farmers driven, we assume that the increasing in family size, farmers will produce the quality and quantity of huge demand product, the farmers will be involved in the standardization; the lower average household income of the general will increase farmers Agriculture standardized production; if the farmers' main source of income is that they join in the agriculture production, the farmers will have eager to participate in standardization.

\subsection{Cognitive characteristics of agricultural standardization variables affect farmers in the standardization of agricultural production}

This variables includ farmers' awareness of standardization of agricultural production (X7), hazard awareness of agricultural inputs (X8), and the use of agricultural inputs (X9). Assuming that the deeper level of understanding in standardization of agricultural production farmers have, the more participate in standardization of agricultural production. Agricultural inputs at the farm on cognitive damage, mainly take pesticides as an example. In general, the deeper understanding farmers of the hazards of agricultural inputs will make them mostly join into the standardization of agricultural production. Also in the use of agricultural inputs, if more using guide for the government or others, will enhance the farmers participate in behavior.

\subsection{Environmental characteristic variables affect farmers to involve in agricultural production}

Environmental characteristic variables include the surrounding production environment of agricultural products and farmers market environment. Farmers market environment includes the commercialization of product(X10), sales channel (X11), the surrounding production environment includes the impact with surrounding Organization for Standardization(X12), production habits (X13). This paper assumes that the higher farmers produce degree of commercialization the more farmers will participate in the standardization; agricultural marketing channels include retail market, enterprise unified purchase, acquisition and other forms of government, in general, the retail market is the largest risk, acquisitions of company takes second, the acquisition of government is more stable. As a very conservatives and risk averse, more stable agricultural marketing channels will be selected to enhance farmers to participate in standardization; the standardization of agricultural production arounding will 
affect farmers to join in the standardization. If the farmers involved in cooperatives or organizations, lead by enterprises in the industry, and there are many standardized production of local organizations, the farmers will be more happy to join the standardization of agricultural production; at the same time, the farmers if the government or others are in accordance with the guidance of production, will involve in agricultural standardization more intensely.

\section{The model construction and data sources}

\subsection{Measurement model}

According to the above-analysised, the paper establishs empirical model of agricultural standardization production that farmers involved in as followed:

$$
Y_{i}=F\left(X_{1}, X_{2}, X_{3}, \cdots, X_{14}, X_{15}, \varepsilon_{i}\right)
$$

Among it, $Y_{i}$ stands the function of farmers' active involved in standardization of agricultural production, $\varepsilon_{i}$ reflects the factors which cannot be observed, it's random disturbance term. $Y_{i}$ depends on $X_{i}$ (the implementation of standardization of agricultural production of farmers of various factors). Respectiving as $\mathrm{Y}=$ 0 and $\mathrm{Y}=1, \mathrm{Y}=0$ stands that farmers choose not to participate in standardization of agricultural production while $\mathrm{Y}=1$ stands farmers participate in standardization of agricultural production. Because the dependent variable is dichotomous virtual coding qualitative variables, we can choose Logistic regression analysis in this study to test the hypothesis. The model makes $[0,1]$ as the dependent variable range, and it is expressed in the form followed:

$$
P_{i}=Y\left(\alpha+\sum_{j=1}^{m} \beta_{i} x_{i j}\right)=1 /\left[1+\exp -\left(\alpha+\sum_{j=1}^{m} \beta_{i} x_{i j}\right)\right],
$$

From this form, $P_{i}$ is the probability of farmers involved in agricultural standardization, $i$ is the household number, $\beta_{i}$ is the factors of regression coefficient, $m$ is the number of factors those influence $\beta_{i}, x_{i j}$ is one of the first $j$ factors, $\alpha$ indicated that regression intercept.

\subsection{Variables explaination}

According to the above theoretical analysis, hypothesis and model selection, this article will make the impact factors of famers involved in standardization of agricultural production divide into five categories, a total of 15 indicators. For variable definitions and statistical variables described in Table 1.

\subsection{Data sources}

This paper uses the data which carried out from farmers in Sichuan province survey in 2010, the author and the research students group of National Philosophy and Social Science Fund, "China's system of agricultural products quality and safety" participated in the survey. According to Sichuan provinces and cities under the economic, physical and other conditions, as well as construction of agricultural standardization demonstration area, finally selected Qionglai Wenjiang, Qiongzhou and other places in Yaan City which are major national, provincial agricultural demonstration zones. Investigating the implementation of local agricultural standardization are good areas.

Located in the hinterland of Chengdu Plain, Wenjiang which is the main crops of garlic, rice etc., has a good location and resource advantages, and builts the provincial agricultural standardization demonstration area in 2002. Qionglai is rich with Kiwi fruit and pigs which in Sichuan are also standardized certain reputation. Chongzhou Mountain and Hilly Areas have good conditions to build Bulangli, access to construction in Sichuan Province in 2007, Lee Brown, pollution-free high-quality standardized demonstration projects approved by the county, the agricultural standardization, and the effection is obvious. Yaan is famous with tea. Mingshan in favorable natural conditions, constructed of state-level agricultural demonstration zonesin 1998 with remarkable results.Yucheng District is also involved in the 2002 national agricultural standardization demonstration district.

Each local surveys 30 questionnaire, a total of 120 samples. There are recovered 110, 6 removed invalid and incompleted questionnaires, 104 valid questionnaires were eventually obtained, the effective return rate of $86.67 \%$. Point of view from the effective questionnaires, the researchers are mainly involved in agricultural standardization due to learning technologies and increasing income. To increase income for the purpose is 41 persons, accounting for $39.4 \%$, while 23 persons are for the purpose of learning technologies, accounting for $22.1 \%$, both these two purposes are 28 , accounting for $26.9 \%$, other purposes are 12 , accounting for $11.6 \%$, that the questionnaire indicated that farmers involved in the standardization with clear intention or not. In addition, 
investigators who have been involved in agricultural standardization are 76 households, of which 40 women, accounting for $52.6 \%, 36$ male, $47.4 \%$; 10 people are above the age of 51,45 people are $31-50$ year-old, 21 people are between 18 and30; primary and lower culture is 9 persons, junior high school is 58 , high school and above is 9; family size 1-2 is 1 person, 3-4 is 9 persons, 5-6 is 17 , above 7 is 11 persons. Farmers who did not participate in standardization are 28 households. 14 were women, accounting for $50 \%, 14$ men, 50\%;51 people are over the age of 22 years, $31-50$ is 6 persons, $18-30$ years old is 0 ; primary and lower culture is 19 , junior is 8 people, high school and above is 1 person; family size 1-2 is $0,3-4$ for $0,5-6$ is 17 people, 7 persons and over is 11 people. Basic sample is shown in Table 2.

\section{Model Estimation and analysis}

\subsection{Model Estimation}

Using SPSS17.0, this paper puts the data back into the Logistic model, and reieves the correlation coefficient of each variable, of which in addition to age and family size, age and hazard of inputs awareness, sources of income and the surrounding standardized impact, sources of income and per capita net income, input use and standardization organizations around the outside of the correlation coefficient is higher, most of the variables correlation coefficients are smaller, these indicated that there are no significant variables multicollinearity problems. In the regression results (Table 3), the data selection criteria for the variable level is a $=0.05$, excluding the standard level of the variable is $a=0.1$. Model chi-square test value is $p=0.000$, less than 0.05 , the model has at least one variable coefficient which is not 0 , having statistical significance; model to predict the correct standard in agriculture is $94.7 \%$, the right rate which not to participate in agricultural standardization is $82.1 \%$, the overall prediction accuracy rate is $91.3 \%$; model $-2 \mathrm{LL}$ is 33.492 , so the model's goodness of fit is good.

\subsection{Results of analysis}

(1)Table 3 shows that age X2, education level X3, the per capita net income X6, standardized cognitive X7, put hazard perception X8, input use X9, Sales channels X11 are Consistented with assumptions which received empirical support; and the other variables are inconsistent with assumptions. Possible reasons are:

A. Young male farmers mostly work outside, so that women children and the elderly stay at home and often play a decisive role, thus gender take reverse affect;

B.Household size is inconsistent with the hypothesis because the left in rural areas has less labor, and farmers are more willing to participate in standardization in order to reduce the burden of production;

C. In addition, farmers'main income comes from non-agricultural, so they have no time to participate in agricultural production, they are more willing to accept the support of government and enterprises to join standards organizations;

D. The phenomenon that the higher the degree of commercialization of agricultural products, the more farmers do not participate in standardization of agricultural production may due to the production of existing demonstration area and farmers affected by their own source of income, they have less the part of agricultural products to sold, most to self-sufficiency, and the commercialization may have the opposite impact on the role;

E. The surrounding environment may have the reverse affect on thefarmers' behavior of agricultural standardization. The reason is the production of household and personal production around are more due to their experience.

(2) From Table 3, in a significant level of $95 \%$, farmers involved in agricultural standardization may be affected by X2, X4, X7, X8; in the significant level of $90 \%, \mathrm{X} 1$ and X11 also has significant affect. According to Sig values, the significantly decreasing order is $\mathrm{X} 7, \mathrm{X} 2, \mathrm{X} 8, \mathrm{X} 4, \mathrm{X} 1, \mathrm{X} 11$, that is farmers on the standardization of knowledge, age, awareness of the harm of inputs, household size, gender, and sales channels. The left variables such as educational level, family characteristics, the degree of commercialization of agricultural products, as well as the surrounding environment, production practices and other factors used in the region the behavior of households involved in agricultural standardization have no significant impact. May be due to these resons:

A. Selecting the standardization of agricultural households needs farmers to haove a stronger ability to accept new things. So household age, household size, gender indicators for farmers involved in agricultural standardization have significantly affected. Standardized cognitive and the hazards of pesticides cognitive will affect farmers to involve in agricultural standardization. The increasing of government acquisitions, corporate uniform increase in the acquisition of other sales channels will lead to increasing farmers to participate in standardization of agricultural production. This indicates that a stable sales channels will significantly affect farmers to participate in the standardization of agricultural production. 
B. The education level has no significant affect on farmers'behavior of participation in agricultural standardization. Many farmers in the production process act according to their own experiences, and the participation of agricultural standardization active should not be considered as a technical choice behavior, so the education level has weakenly impact on the role of agricultural standardization;

C. At this stage, the majority of farmers do agricultural production for self-sufficiency, less commercialized, so it has little impact on participation in standardization.

D. The surrounding environment on the behavior of households involved in agricultural standardization was not significant. May be the questionnaire's choice is farmers in the reason demonstration area, in the surrounding there is a certain standardization of agricultural production organization.

(3) In Table 3, farmers individual, family, cognitive and other characteristics are more prominent than environmental variables. Farmers may be due to the traditional and conservative ideas of their behavior and their behavior is difficult to determine by outside influence.

\section{Conclusion and policy recommendations}

\subsection{Conclusion}

Above discussed-analysis, Sichuan's Farmers who are participation in standardization of agricultural production have affected by the standardized perception, hazard recognition inputs, age, family size, gender, and agricultural marketing channels. In addition to gender, family size, other factors paly a positive role to people involved in standardization of agricultural production. Overall, the behavior of farmers to participate in agricultural standardization is strengthening. However, because of the farmers conservative ideas, they make their participation in the standardization of agricultural production mainly in support of the government and the promotion of the demonstration area, farmers are less conscious in accordance with the standards of production, many by experiences. The main reason is that farmers are lack of awareness of agricultural standardization, the own factors such as age, unstable sales channels of agricultural products and there is some difficulty in sale and such problems.

\subsection{Policy recommendations}

To solve these problems, we propose the following policy recommendations:

(1) Government departments should increase the promotion of agricultural standardization

In order to enhance farmers to implement standardization of agricultural production will, the government should increase efforts to promote agricultural standardization. Government departments can take the training seminars for farmers directly to teach some knowledges of popularity of agricultural standardization, and enhance farmers for agricultural inputs (such as pesticides) hazard awareness; and also can be driven through a big way to strengthen the small households awareness of agricultural standardization, that is to play big role model of agricultural production, to lead the majority of small farmers production; also can assign technical staff "up the hill to the countryside", to guid on-site the farmers for production. So let the farmers know that the standard product, the product brand will be involved in agricultural standardization is the premise of improving product revenue.

\section{(2) Attract young farmers to get rich in their hometowns}

In a long time, most of young adults go outside to work,so force to stay engaged in agricultural production in rural areas are only for the elderly, women and children. Labor age and number are restricting the agricultural standardization work. The Government should properly handle with the issue of migrant workers, and carry out preferential policies to encourage migrant workers to return home, such as increaseing and supporting business opportunities, also can guide the leading agricultural enterprises or enterprises to enter the rural labor force to attract young adults back to rural.

(3) Stable sales channels to solve the worries of farmers

Involved in agricultural households standardized production, farmers are affected by sales channel, so the establishment of agricultural logistics standardization is necessary. Establishing three market circulation of agricultural products (agricultural produce wholesale market, sales in wholesale, retail and farmers market), and establishing the regional integrated logistics and distribution agricultural products system, can connect the bulk of agricultural products, fresh areas of logistics and supermarket chains, so that it will have a smooth sales of agricultural products channels for farmers, and make farmers fell "rest assured that grain," "kind of assured grain."

In summary, the study of its root causes, is that only increasing their income, so that farmers feel so true to bring the benefits of agricultural standardization which can is the key to solve the standardization of agricultural 
production to farmers and enhance the confidence of farmers. Increasing their farming income with a variety of ways, including to enhance the added value of agricultural products is most prominent. Now many farmers sold agricultural primary products, through the introduction of advanced agricultural production equipment to product, package and market the agricultural products, so that make the production has the market prices.

\section{References}

Feng Zhongze,Liqing Jiang. (2007). Farmers about agricultural products quality and safety awareness and influencing factors. Agricultural economic problems, 4, 22-26.

Li Dongmei, Liu Zhi, Tang Shu etc. (2009). Farmers select new varieties of rice and influencing factors. Agricultural economic issues, 11, 44-50.

Louxu Hai, Wang Fang, Chen Song etc. (2007Supplement). Small farmers in Henan Province standardization of agricultural production's influence factors. Agricultural economic problems, 51-54.

Qiao Juan, Cao Lei. (2009). Based on household food security awareness, behavior, attitude and willingness analysis. Chinese Journal of Animal Science, 14, 24-28.

Wang Fang, Chen Song, Fan Hongping etc. (2007). A Theoretical and Empirical Analysis to farmers implement standardization of agricultural production. Agricultural economic issues, 12, 75-78.

Xiong Minghua. (2004). Zhejiang Provincial Development Strategy of Agricultural Standardization. Zhejiang: Zhejiang University.

Zhang Lingguang, Wang Ming Yuan, Xuan Dongan etc. (2004). Agricultural Standardization. Beijing: China Metrology Press. pp. 26-29.

Zhang Yunhua. (2004). Kong Xiangzhi etc. farmers use pesticide pollution and the behavior of green factors. China's rural economy, 1, 41-49.

Zhou Jiehong. (2006). Household vegetable quality and safety control of behavior and influencing factors.

Chinese Rural Economy, 11, 25-34.

Table 1. Model variables' meaning, mean,expected direction

\begin{tabular}{|c|c|c|c|c|}
\hline \multicolumn{2}{|c|}{ Model variables } & Variables' meaning & Mean & Expected direction \\
\hline Dependent variable & Farmers are involved or not $\mathrm{Y}$ & $0=$ involve; $1=$ not involve & & \\
\hline \multirow{3}{*}{$\begin{array}{l}\text { Personal } \\
\text { characteristics }\end{array}$} & SexX1 & $0=$ female; $1=$ male & ----- & + \\
\hline & AgeX2 & $\begin{array}{l}1=\text { above } 51 ; \quad 2=\text { between } 31 \text { and } 50 ; \\
3=\text { between } 18 \text { and } 30\end{array}$ & 1.89 & + \\
\hline & Education X3 & $\begin{array}{l}1=\text { bellow primary schools; } 2=\text { middle } \\
\text { school; } 3=\text { high school and above }\end{array}$ & 1.83 & + \\
\hline \multirow{3}{*}{$\begin{array}{l}\text { Family } \\
\text { characteristics }\end{array}$} & Family sizeX4 & $1=1-2 ; 2=3-4 ; 3=5-6 ; 4=7$ or more & 3.25 & + \\
\hline & Main source of incomeX5 & $\begin{array}{l}1=\text { migrant workers; } 2=\text { business; } 3= \\
\text { agriculture; } 4=\text { Other }\end{array}$ & ----- & + \\
\hline & Per capita incomeX6 & $\begin{array}{l}1=2,000 \text { yuan; } 2=2000-5000 \text { yuan; } 3= \\
5,000-10,000 \text { yuan; } 4=\text { more than } 10,000 \text { yuan }\end{array}$ & 2.68 & +- \\
\hline \multirow[t]{3}{*}{$\begin{array}{l}\text { Cognitive } \\
\text { characteristics }\end{array}$} & Standardized cognitive $\mathrm{X} 7$ & $\begin{array}{l}1=\text { heard of; } 2=\text { image; } 3=\text { heard of; } 4= \\
\text { often heard }\end{array}$ & 2.52 & + \\
\hline & Hazard recognition inputX8 & $\begin{array}{l}1=\text { not clear; } 2=\text { understanding; } 3=\text { clear; } 4 \\
=\text { very clear }\end{array}$ & 2.81 & + \\
\hline & How to use inputs $\mathrm{X} 9$ & $\begin{array}{l}1=\text { rule of experience } ; 2=\text { qacquaintances; } \\
3=\text { technical guidance } 4=\text { Other }\end{array}$ & ------ & + \\
\hline \multirow{4}{*}{$\begin{array}{l}\text { Environmental } \\
\text { characteristics }\end{array}$} & CommercializationX10 & $\begin{array}{l}1=\text { Full retention; } 2=\text { a small part of the } \\
\text { sale; } 3=\text { most of the sale; } 4=\text { all sales }\end{array}$ & 2.16 & + \\
\hline & Marketing channelX11 & $\begin{array}{l}1=\text { market retail; } 2=\text { enterprise unified } \\
\text { acquisition; } 3=\text { government purchases; } 4= \\
\text { Other }\end{array}$ & ------ & + \\
\hline & $\begin{array}{l}\text { Peripheral Organization for } \\
\text { StandardizationX12 }\end{array}$ & $\begin{array}{l}1=\text { do not know; } 2=\text { No; } 3=\text { a little; } 4=a \\
\text { lot }\end{array}$ & 2.99 & + \\
\hline & Production practices $\mathrm{X} 13$ & $\begin{array}{l}1=\text { experience; } 2=\text { acquaintances; } \\
3=\text { technical guidance; } 4=\text { Other }\end{array}$ & ------ & + \\
\hline
\end{tabular}

Note: The table " $4=$ other" are representative of both the case of the first three 
Table 2. The basic situation of the sample

\begin{tabular}{|c|c|c|c|c|c|}
\hline \multirow{2}{*}{\multicolumn{3}{|c|}{ Project }} & \multicolumn{2}{|c|}{$\begin{array}{c}\text { Agricultural standardization } \\
\text { production behavior }\end{array}$} & \multirow[t]{2}{*}{$\begin{array}{r}\text { Total } \\
\text { nunber }\end{array}$} \\
\hline & & & involved & not involved & \\
\hline \multirow{4}{*}{$\operatorname{sex}$} & \multirow[t]{2}{*}{ female } & nunber & 40 & 14 & 54 \\
\hline & & ratio & $52.6 \%$ & $50 \%$ & $51.9 \%$ \\
\hline & \multirow[t]{2}{*}{ male } & nunber & 36 & 14 & 40 \\
\hline & & ratio & $47.4 \%$ & $50 \%$ & $48.1 \%$ \\
\hline \multirow{3}{*}{ age } & above 51 & nunber & 10 & 22 & 32 \\
\hline & $31-50$ & nunber & 45 & 6 & 51 \\
\hline & $18-30$ & nunber & 21 & 0 & 21 \\
\hline \multirow{3}{*}{$\begin{array}{l}\text { education } \\
\text { level }\end{array}$} & $\begin{array}{l}\text { primary school and } \\
\text { below }\end{array}$ & nunber & 9 & 19 & 28 \\
\hline & middle school & nunber & 58 & 8 & 66 \\
\hline & $\begin{array}{l}\text { junior high school } \\
\text { and over }\end{array}$ & nunber & 9 & 1 & 10 \\
\hline
\end{tabular}

Table 3. Logistic model regression results

\begin{tabular}{|c|c|c|c|c|c|c|c|}
\hline Model variables & B & Wals & Sig. & Model variables & B & Wals & Sig. \\
\hline Sex X1 & $-2.472 *$ & 3.082 & .079 & $\begin{array}{l}\text { Hazard recognition } \\
\text { input X8 }\end{array}$ & $3.336^{* *}$ & 5.003 & .025 \\
\hline Age X2 & $5.320 * *$ & 6.042 & .014 & Input use X9 & 1.938 & 2.681 & .102 \\
\hline Education levelX3 & .321 & .083 & .773 & Commercialization X10 & -.119 & .010 & .921 \\
\hline Family sizeX4 & $-2.871 * *$ & 4.422 & .035 & Sales channelsX11 & $2.701 *$ & 3.058 & .080 \\
\hline $\begin{array}{l}\text { Main income } \\
\text { resouses X5 }\end{array}$ & -1.374 & 1.235 & .266 & $\begin{array}{l}\text { Peripheral Organization } \\
\text { for StandardizationX12 }\end{array}$ & -1.043 & 2.235 & .135 \\
\hline $\begin{array}{l}\text { per capita net } \\
\text { income X6 }\end{array}$ & -.167 & .030 & .863 & Production practices $\mathrm{X} 13$ & -.507 & .559 & .455 \\
\hline $\begin{array}{l}\text { Standardized } \\
\text { cognitive X7 }\end{array}$ & $2.256^{* * *}$ & 7.869 & .005 & Constant & -10.028 & 1.511 & .219 \\
\hline Comprehensive test & \multicolumn{7}{|c|}{$\begin{array}{l}\text { Chi-square test results: } 87.666 \quad \text { Degree } \\
\text { Significance probability } 0.000\end{array}$} \\
\hline Model fit test & \multicolumn{2}{|c|}{-2LL: 33.492} & \multicolumn{4}{|c|}{ Cox \& Snell $\mathrm{R}^{\wedge} 2: 0.570$} & \\
\hline
\end{tabular}

Note: $* * *, * *$ respectively stand the estimated coefficient which is not equal to zero the level of significance are $10 \%, 5 \%$, $1 \%$

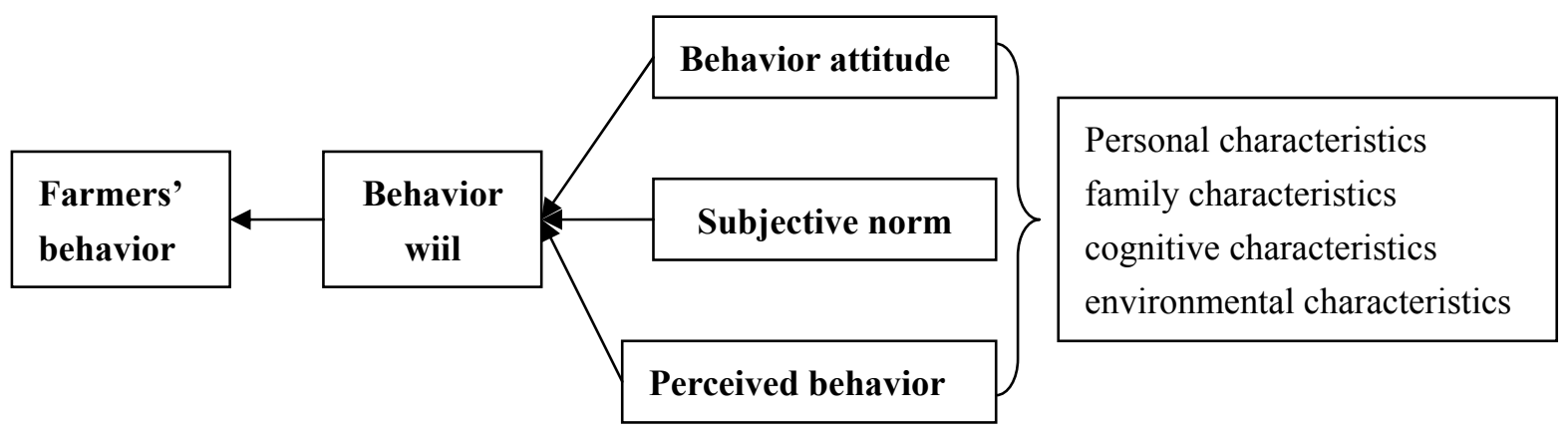

Figure 1. TPB theoretical framework 